Supporting Information for

\title{
Self-nucleation of $\beta$-Form Isotactic Polypropylene Lamellar Crystals in Thin Films
}

\author{
Binghua Wang, Gang Wang, Shanshan He, Taicheng Sun, \\ Jingbo Chen ${ }^{*}$, Changyu Shen, Bin Zhang**
}

School of Materials Science \& Engineering, Zhengzhou University, Zhengzhou

$$
\begin{gathered}
\text { 450001, People's Republic of China } \\
\text { Corresponding authors: } \\
{ }^{*} \text { chenjb@zzu.edu.cn (J. Chen), } \\
{ }^{* *} \text { binzhang@zzu.edu.cn (B. Zhang) }
\end{gathered}
$$




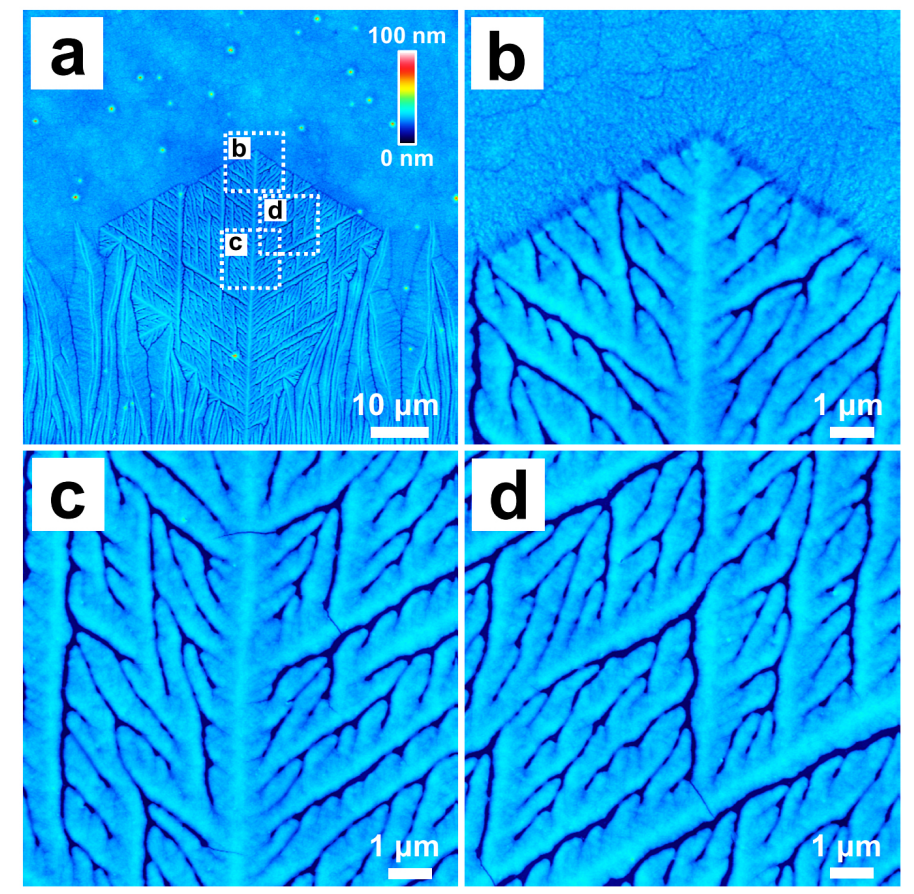

Figure S1. AFM height image of a $\beta$-iPP dendritic crystal obtained by sheared and crystallized at crystallization temperature $T_{\mathrm{c}}=126^{\circ} \mathrm{C}$ in a ca. $23 \mathrm{~nm}$ thick film.
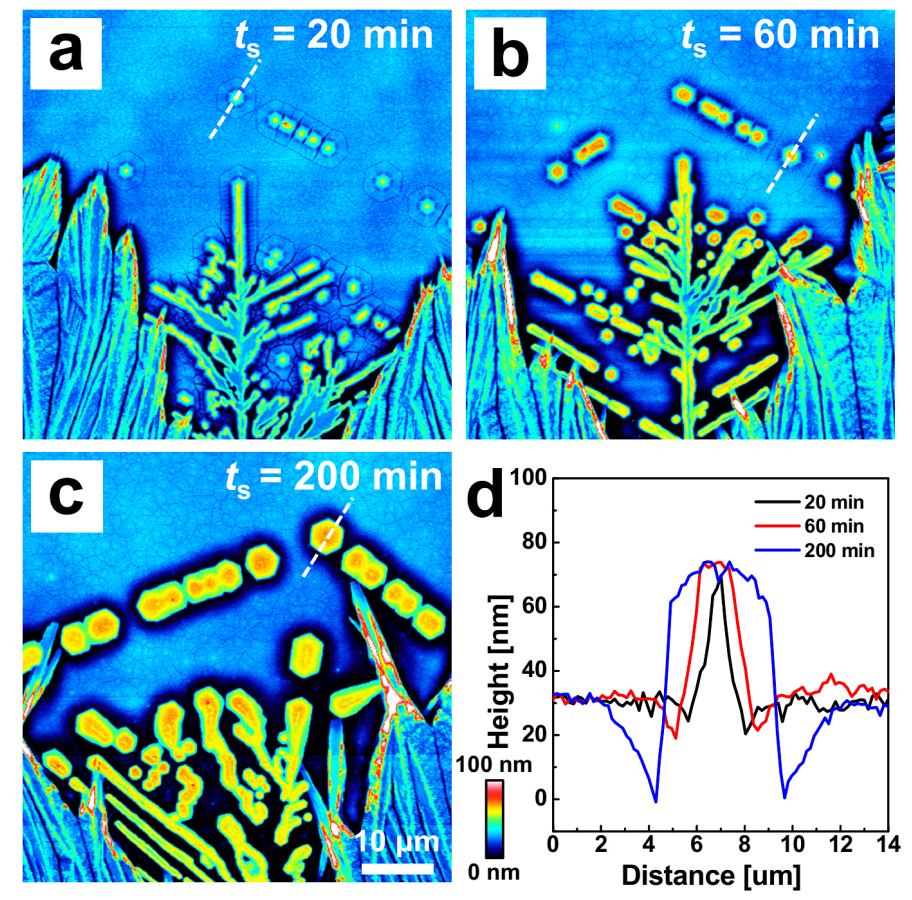

Figure S2. AFM height images measured at room temperature for $\alpha$-iPP and $\beta$-iPP lamellar crystals obtained after annealing at $T_{\mathrm{s}}=T_{\mathrm{c} 2}=154{ }^{\circ} \mathrm{C}$ for $t_{\mathrm{s}}=t_{\mathrm{c} 2}=$ (a) 20, (b) 60 and (c) $200 \mathrm{~min}$, with a heating rate of $20{ }^{\circ} \mathrm{C} / \mathrm{min}$ from $T_{\mathrm{cl}}=136{ }^{\circ} \mathrm{C}$ to $T_{\mathrm{s}}$. Starting $\beta$-iPP crystals were prepared by crystallization at $T_{\mathrm{cl}}=136{ }^{\circ} \mathrm{C}$ for $23 \mathrm{~min}$ in a ca. $40 \mathrm{~nm}$ thick film after shearing at $136{ }^{\circ} \mathrm{C}$. (d) The cross sectional profiles along the directions represented by the dotted white lines in $(\mathrm{a}-\mathrm{c})$. 

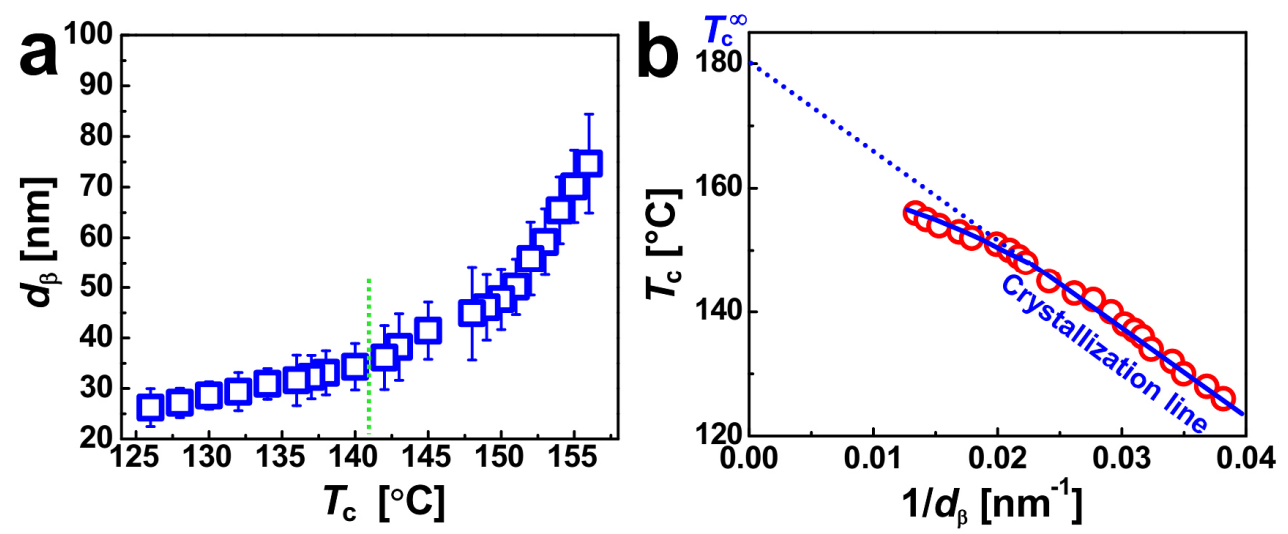

Figure S3 (a) Lamellar thickness of $\beta$-iPP $\left(d_{\beta}\right)$ determined from AFM height images as a function of $T_{\mathrm{c}}$. (b) The $T_{\mathrm{c}}$ against the inverse of $d_{\beta}$.

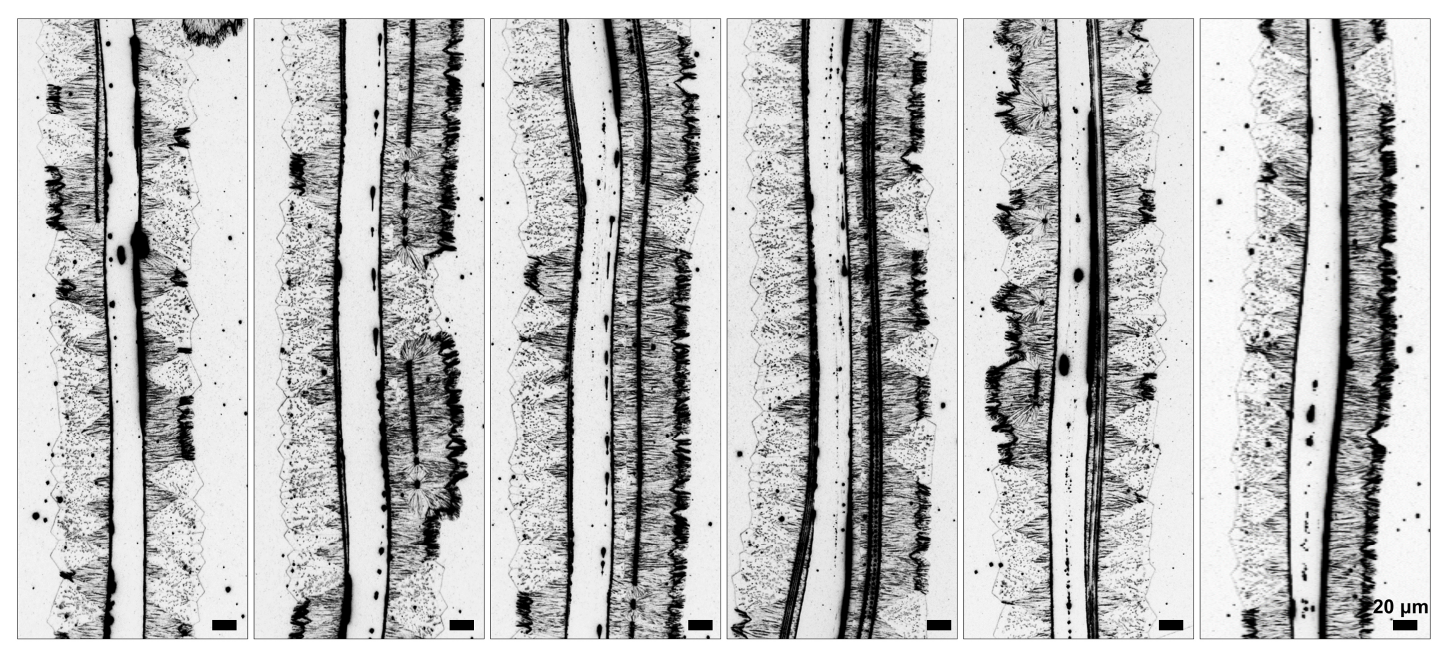

Figure S4. Optical micrographs of the $\alpha$-iPP and $\beta$-iPP crystals obtained by a stepwise crystallization method, varying in $T_{\mathrm{c}}$ and $t_{\mathrm{c}}$ : Step 1. $\left[\left(T_{\mathrm{c} 1-1}, t_{\mathrm{c}}\right)=\left(136{ }^{\circ} \mathrm{C}, 18 \mathrm{~min}\right)\right]$, Step 2 . $\left[\left(T_{\mathrm{c} 1-2}\right.\right.$, $\left.\left.t_{\mathrm{c}}\right)=\left(145^{\circ} \mathrm{C}, 30 \mathrm{~min}\right)\right]$. 